\title{
Exploring awareness of age-related changes among over 50 s in the UK: findings from the PROTECT study
}

\author{
Serena Sabatini, ${ }^{1}$ (1) Obioha C. Ukoumunne, ${ }^{2}$ Clive Ballard, ${ }^{1}$ Rachel Collins, \\ Anne Corbett, ${ }^{1}$ Helen Brooker, ${ }^{1,3}$ and Linda Clare ${ }^{1,2}$ \\ ${ }^{1}$ College of Medicine and Health, University of Exeter, Exeter, United Kingdom \\ ${ }^{2}$ NIHR Applied Research Collaboration South West Peninsula (PenARC), University of Exeter, Exeter, United Kingdom \\ ${ }^{3}$ Ecog Pro Ltd, Bristol, United Kingdom
}

ABSTRACT

Objectives: Older people describe positive and negative age-related changes, but we do not know much about what contributes to make them aware of these changes. We used content analysis to categorize participants' written comments and explored the extent to which the identified categories mapped onto theoretical conceptualizations of influences on awareness of age-related change (AARC).

Design: Cross-sectional observational study.

Participants: The study sample comprised 609 UK individuals aged 50 years or over (mean (SD) age $=67.9$ (7.6) years), enrolled in the PROTECT study.

Measurements: Between January and March 2019, participants provided demographic information, completed a questionnaire assessing awareness of age-related change (AARC-10 SF), and responded to an open-ended question asking them to comment on their responses.

Results: While some of the emerging categories were in line with the existing conceptual framework of AARC (e.g. experiencing negative changes and attitudes toward aging), others were novel (e.g. engagement in purposeful activities or in activities that distract from age-related thoughts). Analysis revealed some of the thought processes involved in selecting responses to the questionnaire items, demonstrating different ways in which people make sense of specific items.

Conclusions: Results support the ability of the AARC questionnaire to capture perceived age-related changes in cognitive functioning, physical and mental health, and engagement in social activities and in healthy and adaptive behaviors. However, findings also suggest ways of enriching the theoretical conceptualization of how AARC develops and offer insights into interpretation of responses to measures of AARC.

Keywords: AARC, subjective aging, prevention, promotion of health, gains, losses

\section{Introduction}

The global proportion of older individuals is increasing, and this results in a growing number of people experiencing both positive and negative age-related changes. Examples of positive changes are greater knowledge, accumulated life experience, and increased leisure time (Carstensen et al., 2011; Carstensen, 1993; Steverink et al., 2001; Timmer et al., 2002), whereas examples of negative changes

Correspondence should be addressed to: Serena Sabatini, Centre for Research in Ageing and Cognitive Health (REACH), University of Exeter, South Cloisters, St Luke's Campus, Exeter EX12LU, U.K. Phone: + 01392726754. Email: s.sabatini2@exeter.ac.uk. Received 24 Apr 2021; revision requested 15 Jul 2021; revised version received 03 Aug 2021; accepted 02 Sep 2021. First published online 02 November 2021. are poorer mental, physical, and functional health and poorer cognitive performance (Barnett et al., 2012; Kingston et al., 2018; Levy, 2017; Royall et al., 2007; United Nations, 2019).

Maintenance of good health throughout later life is vital for quality of life and for the sustainability of the world health system and economy. The study of self-perceptions of aging (SPA) may suggest ways of promoting health in the second half of life. Indeed, those individuals with positive SPA are more likely to engage in healthy behaviors and to experience better health (Jaconelli et al., 2017; Kornadt et al., 2019; Montepare, 2019; Westerhof et al., 2014) than those with negative SPA. However, the way in which SPA have been conceptualized and measured so far may have resulted in a simplified understanding of 
the relationship between SPA and health (Diehl et al., 2014).

Many existing measures of SPA are unidimensional (e.g. Attitude Toward Own Aging Scale; Lawton, 1975). In this way, respondents can report either negative or positive SPA, but not both. However, developmental gains and losses coexist throughout the lifespan (Baltes, 1987; Miche et al., 2014). Moreover, many measures provide global evaluations of SPA (e.g. subjective age; Barrett, 2003) even though individuals can experience different perceptions of aging in relation to distinct life domains (e.g. social, cognitive, physical; Carstensen et al., 2011; Sabatini et al., In Press; Steverink et al., 2001; Voss et al., 2018). The concept of awareness of age-related change (AARC) aims to overcome these limitations (Diehl and Wahl, 2010; Diehl et al., 2014) by capturing self-perceptions of positive (gains) and negative (losses) age-related changes across five life domains: health and physical functioning, cognition, interpersonal relationships, socio-cognitive and socioemotional functioning, and lifestyle/life engagement.

Perceptions of AARC gains and losses are assessed via questionnaire (AARC-10 SF; Kaspar et al., 2019). Items included in the AARC questionnaire are the result of interviews and focus groups where US and German middle-aged and older adults discussed the changes they experienced while getting older. Examples of items assessing AARC gains and losses, respectively, are "With my increasing age, I realize that I have become wiser" and "With my increasing age, I realize that I have less energy." The unique conceptual features of AARC may make it possible to advance our understanding of the mechanisms behind the association of SPA with health. However, so far, little is known about factors that influence and shape AARC.

Based on existing literature on SPA, Diehl and Wahl (2010) proposed an heuristic framework placing the AARC construct into a broader conceptual framework including variables that may act as antecedents of AARC, variables involved in the mental process of AARC, and outcomes of AARC. Hypothesized distal antecedents of AARC comprise sociodemographic (e.g. chronological age and socioeconomic status), health-related factors (e.g. health history and health status), and psychological factors (e.g. personality traits), whereas proximal antecedents include personal goals, life limitations, age stereotypes, and current life events. Hypothesized factors involved in the mental process of AARC include personal meaningmaking and self-regulation of behavior. Finally, hypothesized outcomes of AARC are psychological health, physical health, and life engagement.
The relationships of AARC with some of the variables included in the Diehl and Wahl (2010) conceptual framework have been widely researched, whereas other potential relationships remain unexplored. Examples of known antecedents of AARC are sociodemographic variables and attitudes toward own aging (ATOA; Brothers et al., 2016; 2017; 2020; English et al., 2019; Sabatini et al., 2020b), whereas examples of unexplored factors are social engagement and lifestyle. An example of a variable related to the mental process of AARC is engagement in self-regulatory behaviors (Dutt et al., 2016), whereas an example of an unexplored factor is the interpretation of changes as being a consequence of aging or of other factors such as illnesses (Rothermund et al., 2021). In summary, currently there is no evidence supporting some of the hypothesized predictors of AARC. Moreover, the heuristic framework of AARC, outlined by Diehl and Wahl (2010), does not presume to be comprehensive and additional variables related to AARC are yet to be identified.

In the current study, we therefore aim to increase knowledge about what contributes to making people aware of age-related changes as these develop in the second half of life. This aim will be achieved by qualitatively examining the open-ended comments that individuals aged 50 years and over made when reporting on aspects of AARC. More specifically, we will evaluate the degree to which the comments (grouped into categories) that participants make while answering the AARC questionnaire map onto the variables (i.e. distal antecedents, proximal antecedents, variables involved in the mental process of AARC, and developmental outcomes) hypothesized to be related to AARC in the Diehl and Wahl (2010) conceptual framework of AARC, and/or to new variables that could be added to the Diehl and Wahl (2010) conceptual framework of AARC. Hence, study results may help to better understand and refine the current conceptual framework of AARC.

To achieve our study aim, we will also consider participants' open-ended comments (identified categories) alongside the answers they give to the questionnaire items (their levels of AARC gains and losses). This will make it possible to explore the relative salience of different variables/antecedents (e.g. daily life events) on AARC, and whether different types of thoughts described by participants are differentially related to levels of AARC gains and losses. For instance, individuals who mention having experienced a recent health issue may report higher AARC losses and/or lower AARC gains compared to individuals who do not report a recent health issue. Exploring which factors individuals 
take into consideration when reporting their AARC may extend our understanding of why AARC is associated with health outcomes.

The current study will gather new evidence on AARC in several ways. First, although the study by Miche et al. (2014) provided useful insights into factors that trigger perceptions of AARC, this is the only available study on the topic, and it is limited in that it focused exclusively on reports of daily events. This study, therefore, aims to understand whether the formation of age-related thoughts is influenced by broader psychosocial factors as this has never been investigated with qualitative analysis. Second, in their study, Miche et al. (2014) included only participants aged 70 years and over. However, perceptions of age-related change become salient from middle-age (Kornadt et al., 2018) and, due to the good health that generally characterizes middleaged individuals (Balcombe and Sinclair, 2001), events related to AARC in this age group may be different. The current study therefore explores a wider range of factors associated with AARC across the second half of life to reach a more comprehensive understanding of how AARC is formed.

Third, this study will explore for the first time the thoughts that UK residents report in relation to AARC. Indeed, although the short form of the AARC questionnaire has recently been validated within the UK population (Sabatini et al., 2020b), qualitative accounts in relation to the AARC questionnaire have never been explored among UK individuals. This is important given that factors related to AARC seem to vary across cultures (Sabatini et al., 2020a). Fourth, exploration of participants' thoughts in relation to the AARC questionnaire may provide additional information on the use of the AARC questionnaire in the UK and, therefore, complement the psychometric validation of the AARC questionnaire in this country. For instance, this study may identify issues (such as interpretation of the meaning of items) that UK individuals report in relation to the items included in the AARC questionnaire.

\section{Methods}

\section{Study design and participants}

Analyses were conducted on cross-sectional data collected as part of the PROTECT study (https:// www.protectstudy.org.uk). Participants were 609 UK individuals aged 50 years or over $(\mathrm{M}$ age $=$ 67.9 years; $\mathrm{SD}=7.6$ ). The majority of participants in the current study were women, White, married, and nonworking (see Table 1). Further information on study design and participants is provided in Supplementary Text 1 .

\section{Measures}

Demographic variables included age, sex, marital status (married and not married), education level (secondary, post-secondary, vocational qualification, undergraduate degree, postgraduate degree, and doctorate), and employment (employed and not employed). AARC was assessed with the AARC-10 SF (Kaspar et al., 2019) which includes 10 items, 5 measuring gains, and 5 measuring losses across the 5 AARC life domains. Respondents evaluate how much items apply to them on a five-point scale (1 - "Not at all"; 2 - "a little bit"; 3 "moderately"; 4 - "quite a bit"; 5 - "very much"). Totals scores for each of the gains and losses scales are obtained by summing items belonging to the respective scales and range from a possible 5 to 25; higher scores indicate higher levels of AARC. In the UK validation of the AARC-10 SF, the Cronbach's alpha $(\alpha)$ measure of internal consistency was 0.77 for the gains subscale and 0.80 for the losses subscale (Sabatini et al., 2020b). The following open-ended question was used to ask participants to add their thoughts regarding AARC: "If you wish, please add any additional information or comments for this section in the box below." This question was asked only once after the completion of the AARC-10 SF.

\section{Data analyses}

Content analysis was applied to participants' answers to the AARC open-ended question (Grbich, 2012; Pope et al., 2000). The first author manually analyzed the data using the following steps: (1) data familiarization through reading and rereading participants' responses (Polit and Beck, 2004) and (2) definition of the categories and manual assignment of participants' comments to categories. When appropriate, participants' statements were assigned to more than one category (Richards, 2015); (3) visual presentation of categories in a diagram. Further information on qualitative analyses is provided in Supplementary Text 1.

As quantitative data can contribute to the interpretation of meaning in qualitative accounts (Sandelowski and Barroso, 2003), we calculated the number of participants whose comments were assigned to each of the identified categories. We used the $t$-test to compare the mean AARC gains and losses scores between those individuals whose comments were assigned to a specific category and those individuals who were not. This enabled us to understand whether the experience of certain life events and/or psychosocial factors makes individuals more likely to perceive higher or lower levels of AARC gains and losses. Hedges's $g$ was used to quantify effect size (Lakens, 2013). Effect sizes of 0.2, 0.5, 
Table 1. Demographic characteristics of PROTECT participants who answered and who did not answer the AARC open-ended question

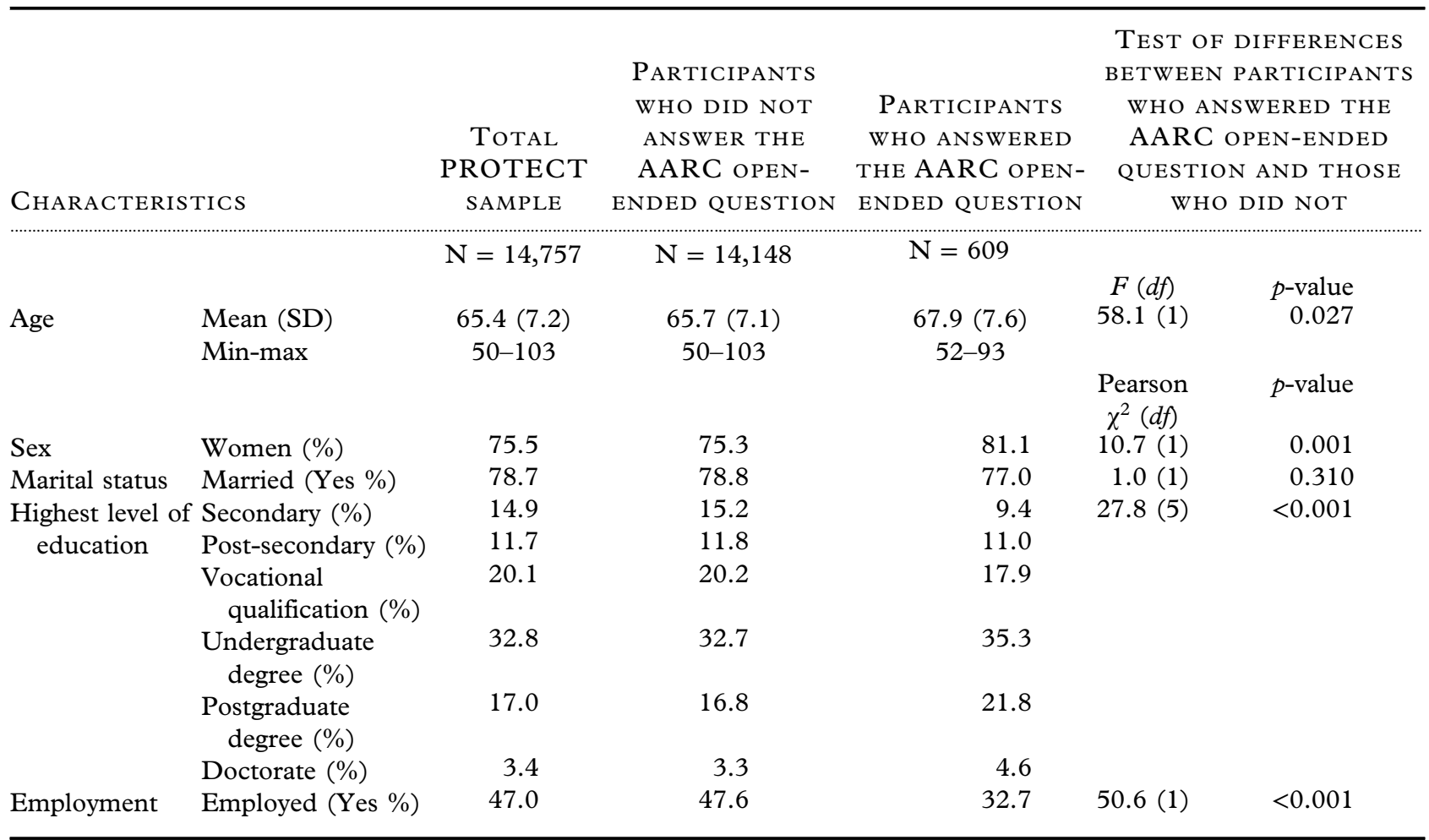

Total PROTECT sample including participants who took part in the PROTECT study between 1 January 2019 and 31 March 2019. Participants who did not answer the AARC open-ended question includes all the participants who were part of the PROTECT study between 1 January 2019 and 31 March 2019 but did not answer the AARC open-ended question. Total study sample in this paper comprises participants who in 2019 answered the AARC open-ended question.

and 0.8 are considered small, medium, and large effects, respectively.

\section{Results}

\section{Descriptive analysis}

Descriptive statistics are reported in Table 1 for all participants who took part in PROTECT in 2019, for the subgroup of participants that took part in PROTECT in 2019 but did not answer the AARC open-ended question, and for the subsample who answered the AARC open-ended question. In this last subsample, participants on average perceived "moderate levels" of AARC gains and "a little bit" of losses. Table 1 reports analyses of differences among the subsamples who did and did not answer the open-ended question. Compared to the sample of participants who did not complete the AARC openended question, the subsample who completed it included more individuals who were women, bettereducated, and not in paid employment.

\section{Comments associated with AARC judgments}

The mean length of comments was 1.5 sentences per participant, although length varied considerably and ranged from a short sentence of 3 words to 10 sentences. From analysis of participants' comments about their AARC, 10 categories capturing comments associated with AARC were generated and grouped into 3 higher-order categories (Figure 1 illustrates how we hypothesized the categories may be related). The first higher-order category covers "subjective experiences while aging" and includes five categories: "experiencing negative changes," "experiencing positive changes," "attitudes toward aging," "feeling unchanged," and "purpose-driven experiences." The second higher-order category captures "factors impacting evaluation of awareness of changes" and includes three categories: "fluctuating levels of awareness of changes," "disregarding the impact of increased age," and "difficulty when answering the AARC questionnaire." The third higher-order category describes the "process of awareness of changes" and includes two categories: "healthy lifestyle and selfregulation" and "social comparison."

\section{Subjective experiences while aging}

Examples of participants' comments for the identified categories are presented in Table 2. The higherorder category "Subjective experiences while aging" describes factors that can increase or decrease 


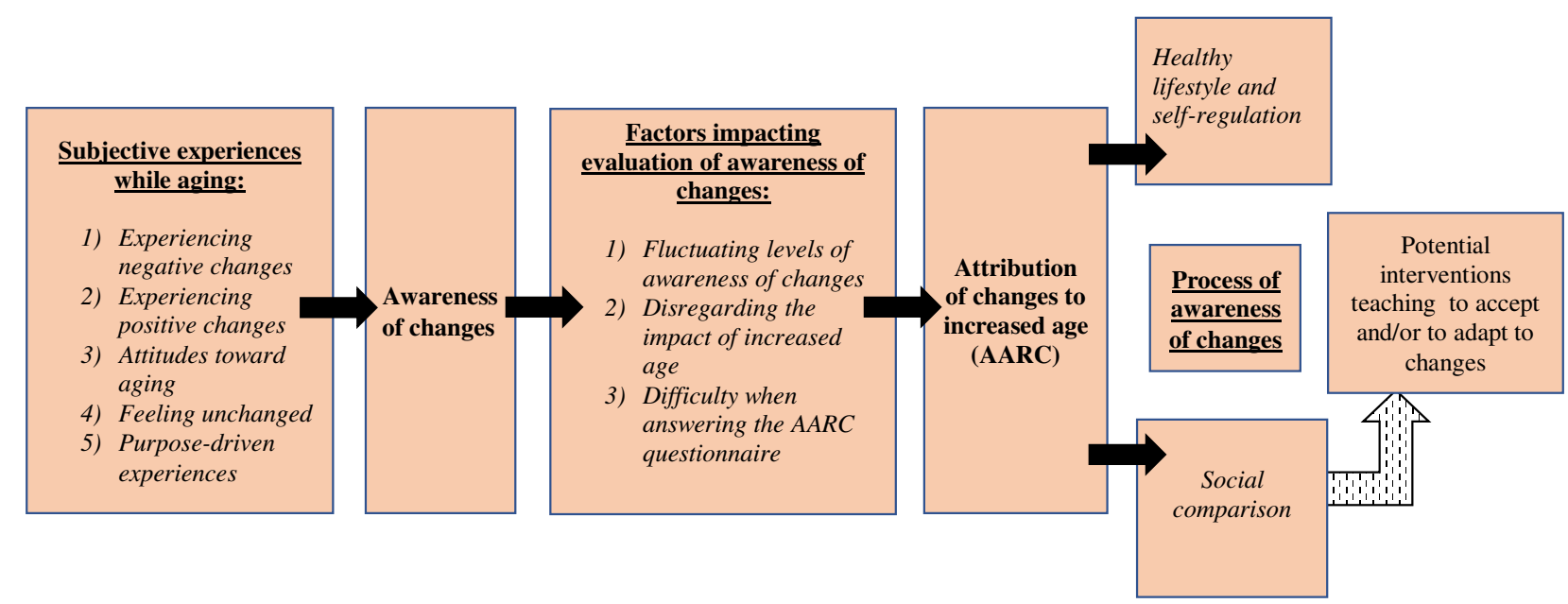

Figure 1. The thematic map illustrates the hypothesis of how the 10 categories identified through content analyses may be interrelated. Categories are organized into predictors of AARC (listed under the heading "subjective experiences while aging"), factors explaining lack of accuracy in AARC (listed under the heading "factors impacting evaluation of awareness of changes"), and factors involved in the mental process of AARC.

awareness of changes. Some participants $(33.3 \%$ of the current study sample $(\mathrm{N}=609)$ ) experienced negative changes across various life domains such as physical and cognitive domains. Changes in the physical domain included the presence of a chronic health condition, a recent injury or illness, falls, physical pain, decreased energy, and changes in physical appearance. Changes in the cognitive domain related to loss of memory or concentration. However, some participants also experienced positive changes $(18.2 \%$ of the current study sample) that, similar to awareness of negative changes, happened in various domains including mental health (e.g. being happier), physical health, cognitive abilities (e.g. increased knowledge), life engagement (e.g. more time to pursue hobbies), and even characterized their personality (e.g. becoming less impulsive).

For some participants, awareness of changes was influenced by their attitudes toward aging and life in general $(6.7 \%$ of the current study sample). Some people experienced older age as a positive period of life and perceived older people as competent, whereas others viewed older age as a negative stage of life and believed that older people are fragile and in need of help. For some participants, their attitudes toward life changed while aging; for instance, individuals become more aware of the finitude of life or shift their focus from the future to the present.

Other participants instead felt unchanged or at least felt that some aspects of their lives, attitudes, or behaviors had not changed with their increased age ( $28 \%$ of the current study sample). Finally, another factor that some participants $(12.8 \%$ of the current study sample) described as being related to their awareness of changes is their level of engagement in a variety of activities including work, hobbies (e.g. traveling), or caring for someone living with an illness or for grandchildren. Being able to conduct specific activities made some participants feel competent or conferred a sense of purpose. For other individuals having several commitments left them little time to reflect on the age-related changes they were experiencing, resulting in lower levels of awareness of changes.

FACTORS IMPACTING EVALUATION OF AWARENESS OF CHANGES

In the higher-order category "Factors impacting evaluation of awareness of changes" participants remarked how several factors can influence the levels of changes they perceive. First, a small proportion of participants $(1.2 \%$ of the current study sample) reported that their AARC fluctuates depending on several factors such as the situation they are in. Many individuals (31.3\% of the current study sample), despite acknowledging the presence of relevant, specific changes in their life, clarified that such changes are not due to their increased age. Instead, participants identified various factors that in their opinion cause the experienced changes, including being a caregiver, a recent bereavement, financial restrictions, societal changes, a physical condition, the menopause, and a mental health issue. Finally, some individuals ( $6.2 \%$ of the current study sample) had difficulty in answering the AARC questionnaire due to being forced to choose an answer where they would have preferred a non-applicable option, finding items to be vague or not understanding the specific meaning. Overall, the above-described factors impacted on the scores that a relevant proportion of participants obtained on the AARC 
Table 2. Examples of participants' comments per each of the identified categories

\begin{tabular}{lc}
\hline $\begin{array}{l}\text { HIGHER-ORDER } \\
\text { CATEGORIES }\end{array}$ & CATEGORIES \\
\hline $\begin{array}{c}\text { Subjective } \\
\text { experiences } \\
\text { while aging }\end{array}$ & $\begin{array}{c}\text { Experiencing negative } \\
\text { changes }\end{array}$ \\
\hline
\end{tabular}

EXAMPLES OF PARTICIPANTS' COMMENTS PER EACH OF THE IDENTIFIED CATEGORIES

"I have recently acquired a nerve injury which affects my mobility" (Woman, 63 years).

"I have polymyalgia rheumatic diagnosed 2 years ago" (Woman, 63 years). "Osteo-arthritis in knees and (sometimes) pain in hips" (Woman, 69 years).

"I would say, I have fewer physical stamina" (Woman, 71 years).

"My appearance e.g. thinning hair affects how I feel about my age" (Woman, 62 years).

"Memory is failing" (Woman, 76 years).

"Sometimes I forget that I have put a teabag into the pot and do it again" (Woman, 65 years).

Experiencing positive changes

Attitudes toward aging

Feeling unchanged

Purpose-driven experiences

Factors impacting evaluation of awareness of changes
"I think I am happier than ever, and more aware of my good fortune in life. I can take more time to enjoy myself and make more of every outing" (Woman, 71 years).

"My general physical and mental well-being improved dramatically after I have retired 5 years ago. My knowledge base, my designing and planning to do things, and my manual work improved many times over" (Man, 67 years).

"Life experience is quite a useful asset" (Woman, 91 years).

"I am more confident in my decisions" (Woman, 58 years).

"Overall I do not feel negative about my age, though it seems many others in my age group appear to have negative thinking" (Woman, 70 years).

"I am quite positive about growing older" (Woman, 56 years).

"Don't believe in using age as a barrier" (Woman, 54 years).

"Don't like getting old, the brain is still willing but the body at times say 'No chance mate!" (Man, 65 years).

"We should all be allowed to book a place at the Vets, be given an injection, die and be buried in our gardens" (Woman, 77 years).

"Getting older is a mixed blessing" (Woman, 79 years).

"Old age isn't for the faint hearted" (Man, 75 years).

"I seem to have lost enthusiasm for life" (Woman, 73 years).

"More aware of mortality" (Woman, 56 years).

"I am realizing, I am no longer immortal!" (Man, 65 years).

"I really don't feel any different" (Woman, 63 years).

"I don't often think or recognize my increasing age" (Woman, 68 years).

"I am a competent administrator and a hard worker" (Woman, 71 years).

"Volunteering in two museums, in addition to a new range of hobbies and pastimes during retirement can be as demanding as working full-time. I enjoy the challenge of new projects" (Woman, 72 years).

"As a wife, mother of 5 children, with 8 grandchildren, active in my community, I do not yet have the time to focus on just my own needs nor to 'have more freedom to live my days the way I want'. But that is not something I aspire to. I enjoy my life the way it is!" (Woman, 67 years).

"As I have children and grandchildren living with me, that keeps me fully occupied" (Woman, 69 years).

"I think my answers could vary from time to time" (Woman, 72 years).

"These answers are all situation dependent" (Woman, 59 years).

"All very dependent on how I wake up in the morning!" (Woman, 83 years).

"My energy levels have become more markedly seasonal - low energy / motivation / activity in winter" (Woman, 65 years).

Disregarding the impact "My husband was very ill last year, and this has affected me in many ways" of increased age (Woman, 72 years).

"Being widowed has made me feel old" (Woman, 77 years).

"Lack of money can be very limiting (Woman, 78 years).

"Some of the answers are affected by my physical condition rather than my age" (Woman, 72 years).

"I think many issues may be due to menopause than age!" (Woman, 62 years). "My bipolar disorder interferes at times with all these" (Woman, 60 years). 


\begin{tabular}{|c|c|c|}
\hline \multirow{2}{*}{$\begin{array}{l}\text { HIGHER-ORDER } \\
\text { CATEGORIES }\end{array}$} & \multirow[b]{2}{*}{ CATEGORIES } & EXAMPLES OF PARTICIPANTS' COMMENTS PER EACH OF THE \\
\hline & & IDENTIFIED CATEGORIES \\
\hline \multirow{3}{*}{$\begin{array}{l}\text { Process of awareness } \\
\text { of changes }\end{array}$} & $\begin{array}{l}\text { Difficulty when answering } \\
\text { the AARC questionnaire }\end{array}$ & $\begin{array}{l}\text { "For some questions none of the answers apply. There should be a not applicable } \\
\text { option"(Woman, } 78 \text { years). } \\
\text { "With my increasing age is too vague. Do you mean in the last five years, or } \\
\text { since I was a child, or since I turned 21, or since I retired?" (Man, 69 years). } \\
\text { "Not sure what foresight means" (Man, } 59 \text { years). }\end{array}$ \\
\hline & $\begin{array}{l}\text { Attention to healthy } \\
\text { lifestyle and adaptation } \\
\text { to AARC }\end{array}$ & $\begin{array}{l}\text { "I have started a beginners French language course to stimulate that part of the } \\
\text { brain" (Woman, } 74 \text { years). } \\
\text { "I have researched the things I can do which may prevent or delay dementia, } \\
\text { and I try to do all of them as often as possible. Since both my parents and sister } \\
\text { had or have dementia, I am committed to a healthy lifestyle, mentally and } \\
\text { physically" (Woman, } 68 \text { years). } \\
\text { "I realize that as I get older, I need to take good care of myself" (Woman, } 63 \\
\text { years). } \\
\text { "I am more inclined to pay to have other people do jobs such as house alterations } \\
\text { which I would previously do myself" (Man, } 77 \text { years). } \\
\text { "I have to do sports in a less extreme way so only windsurf in light winds, ride } \\
\text { quiet horses, less uphill walks" (Woman, } 75 \text { years). } \\
\text { "Rather than brisk walking, these days I prefer to cycle. Less wear and tear on } \\
\text { my knee and hip joints" (Man, } 71 \text { years). }\end{array}$ \\
\hline & Social comparison & $\begin{array}{l}\text { "I feel very fortunate to have the degree of use of all of my faculties that I do have } \\
\text { compared to many other people I see around me of the same age" (Man, } 72 \\
\text { years). } \\
\text { "I have based some of these answers on what other people have told me" } \\
\text { (Woman, } 77 \text { years). }\end{array}$ \\
\hline
\end{tabular}

Table 3. Number (\%) of the study sample who provided responses to the open-ended AARC question that fell into specific categories

\begin{tabular}{llc}
\hline Higher-ORDER CATEGORIES & CATEGORIES & NUMBER $(\%)(\mathrm{N}=609)$ \\
Subjective experiences while aging & Experiencing negative changes & $203(33.3 \%)$ \\
& Experiencing positive changes & $111(18.2 \%)$ \\
& Attitudes toward aging & $41(6.7 \%)$ \\
& Feeling unchanged & $171(28 \%)$ \\
& Purpose-driven experiences & $78(12.8 \%)$ \\
Factors impacting evaluation of & Fluctuating levels of awareness of changes & $7(1.2 \%)$ \\
awareness of changes & Disregarding the impact of increased age & $191(31.3 \%)$ \\
Process of awareness of changes & Difficulty when answering the AARC questionnaire & $38(6.2 \%)$ \\
& Attention to healthy lifestyle and adaptation to AARC & $46(7.5 \%)$ \\
& Social comparison & $9(1.5 \%)$ \\
\hline
\end{tabular}

questionnaire. This may result in decreased accuracy of individuals' scores on the AARC-10 SF.

\section{Process of AwARENess of CHANGes}

The higher-order category "Process of awareness of changes" describes mental processes that can result in intention to react or adapt to changes and mental processes that individuals use to make sense of the changes they experience. A small proportion of people reacted or adapted to AARC losses by abandoning physically demanding activities and hobbies, and engaging in new activities and/or in healthy behaviors $(7.5 \%$ of the current study sample). Few individuals (1.5\%) used mental strategies such as comparing themselves with other people that were in a less advantageous position than them or emphasizing the positive opinion that other individuals had about them. Frequencies for each category for the study sample are presented in Table 3.

\section{Relationships among categories}

The 10 categories are organized in a diagram showing how they are interrelated (Figure 1). The diagram shows how different subjective experiences of aging can lead to varying degrees of awareness of changes, attempts to explain how awareness of 
Table 4a. For each of the 10 categories, the table summarizes comparisons of the mean AARC gain score between individuals whose comments were assigned to a category and individuals whose comments were not assigned to the category

\begin{tabular}{|c|c|c|c|c|c|c|c|}
\hline CATEgories TO THE CATEgory & $\begin{array}{l}\text { ANSWERED OR NOT } \\
\text { OBSERVATIONS }\end{array}$ & $\begin{array}{l}\text { Number of } \\
\text { AARC GAINS }\end{array}$ & $\begin{array}{c}\text { MEAN OF } \\
\text { DEVIATION (SD) }\end{array}$ & STANDARD & $T$-STATISTIC & $P$-VAlUE & HedGes's $G(95 \% \mathrm{CI})$ \\
\hline \multirow[t]{2}{*}{ Experiencing negative changes } & No & 406 & 17.56 & 4.17 & -1.51 & 0.132 & $-.13(-.30$ to .04$)$ \\
\hline & Yes & 203 & 18.09 & 3.78 & & & \\
\hline \multirow[t]{2}{*}{ Experiencing positive changes } & No & 498 & 17.64 & 4.1 & -1.27 & 0.204 & $-.13(-.34$ to .07$)$ \\
\hline & Yes & 111 & 18.18 & 3.78 & & & \\
\hline \multirow[t]{2}{*}{ Attitudes toward aging } & No & 568 & 17.66 & 4.04 & -1.71 & 0.088 & $-.28(-.59$ to .04$)$ \\
\hline & Yes & 41 & 18.78 & 4.02 & & & \\
\hline \multirow[t]{2}{*}{ Feeling unchanged } & No & 438 & 18.08 & 3.95 & 3.33 & 0.001 & $.30(.12$ to .48$)$ \\
\hline & Yes & 171 & 16.87 & 4.17 & & & \\
\hline \multirow[t]{2}{*}{ Purpose - driven experiences } & No & 531 & 17.58 & 4.04 & -2.51 & 0.012 & $-.30(-.54$ to -.66$)$ \\
\hline & Yes & 78 & 18.81 & 3.92 & & & \\
\hline \multirow{2}{*}{$\begin{array}{l}\text { Fluctuating levels of awareness } \\
\text { of changes }\end{array}$} & No & 602 & 17.77 & 4.04 & 1.61 & 0.107 & $-.61(-.13$ to 1.36$)$ \\
\hline & Yes & 7 & 15.29 & 4.23 & & & \\
\hline \multirow{2}{*}{$\begin{array}{l}\text { Disregarding the impact of } \\
\text { increased age }\end{array}$} & No & 418 & 17.59 & 4 & -1.36 & 0.175 & $-.12(-.29$ to -.05$)$ \\
\hline & Yes & 191 & 18.07 & 4.14 & & & \\
\hline Difficulty when answering the & No & 571 & 17.91 & 3.96 & 4.16 & $<.001$ & $.70(.36$ to 1.03$)$ \\
\hline AARC questionnaire & Yes & 38 & 15.13 & 4.5 & & & \\
\hline \multirow{2}{*}{$\begin{array}{l}\text { Attention to healthy lifestyle and } \\
\text { adaptation to AARC }\end{array}$} & No & 563 & 17.63 & 4.01 & -2.36 & 0.019 & $-.36(-.66$ to -.06$)$ \\
\hline & Yes & 46 & 19.09 & 4.29 & & & \\
\hline \multirow[t]{2}{*}{ Social comparison } & No & 600 & 17.72 & 4.05 & 17.4 & 0.39 & $-.29(-.95$ to .37$)$ \\
\hline & Yes & 9 & 11.78 & 4.66 & & & \\
\hline
\end{tabular}


Table $\mathbf{4 b}$. For each of the 10 categories, the table summarizes comparisons of the mean AARC gain score between individuals whose comments were assigned to a category and individuals whose comments were not assigned to the category

\begin{tabular}{|c|c|c|c|c|c|c|c|}
\hline CATEGories & $\begin{array}{l}\text { ANSWERED } \\
\text { OR NOT } \\
\text { TO THE } \\
\text { CATEGORY }\end{array}$ & $\begin{array}{l}\text { Number OF } \\
\text { OBSERVATIONS }\end{array}$ & $\begin{array}{l}\text { MEAN OF AARC } \\
\text { LOSSES }\end{array}$ & $\begin{array}{c}\text { STANDARD } \\
\text { DEVIATION (SD) }\end{array}$ & $T$-STATISTIC & $P$-VALUE & HEDGES's G (95\% CI) \\
\hline \multirow[t]{2}{*}{ Experiencing negative changes } & No & 406 & 10.10 & 3.59 & -2.37 & 0.018 & $-0.20(-0.37$ to -0.03$)$ \\
\hline & Yes & 203 & 10.81 & 30.39 & & & \\
\hline \multirow[t]{2}{*}{ Experiencing positive changes } & No & 498 & 10.42 & 30.57 & 1.37 & 0.171 & $0.14(-0.06-0.35)$ \\
\hline & Yes & 111 & 9.92 & 30.38 & & & \\
\hline \multirow[t]{2}{*}{ Attitudes toward aging } & No & 568 & 10.39 & 30.57 & 1.54 & 0.123 & $0.25(-0.07-0.57)$ \\
\hline & Yes & 41 & 9.51 & 20.97 & & & \\
\hline \multirow[t]{2}{*}{ Feeling unchanged } & No & 438 & 10.85 & 30.67 & 5.95 & $<0.001$ & $0.54(0.36-0.72)$ \\
\hline & Yes & 171 & 9.01 & 20.76 & & & \\
\hline \multirow[t]{2}{*}{ Purpose-driven experiences } & No & 531 & 10.53 & 30.52 & 3.60 & $<0.001$ & $0.44(0.20-0.67)$ \\
\hline & Yes & 78 & 9.0 & 30.40 & & & \\
\hline \multirow{2}{*}{$\begin{array}{l}\text { Fluctuating levels of awareness of } \\
\text { changes }\end{array}$} & No & 602 & 10.28 & 30.50 & -3.87 & $<0.001$ & $-1.47(-2.22$ to -0.72$)$ \\
\hline & Yes & 7 & 15.43 & 30.69 & & & \\
\hline \multirow{2}{*}{$\begin{array}{l}\text { Disregarding the impact of increased } \\
\text { age }\end{array}$} & No & 418 & 10.01 & 30.42 & -3.36 & $<0.001$ & $-0.29(-0.46$ to -0.12$)$ \\
\hline & Yes & 191 & 11.04 & 20.69 & & & \\
\hline \multirow{2}{*}{$\begin{array}{l}\text { Difficulty when answering the AARC } \\
\text { questionnaire }\end{array}$} & No & 571 & 10.38 & 30.58 & 1.12 & 0.262 & $0.19(-0.14-0.52)$ \\
\hline & Yes & 38 & 9.71 & 20.83 & & & \\
\hline \multirow{2}{*}{$\begin{array}{l}\text { Attention to healthy lifestyle and } \\
\text { adaptation to AARC }\end{array}$} & No & 563 & 10.32 & 30.56 & -0.46 & 0.647 & $-0.07(-0.37-0.23)$ \\
\hline & Yes & 46 & 10.57 & 30.34 & & & \\
\hline \multirow[t]{2}{*}{ Social comparison } & No & 600 & 10.31 & 30.52 & -1.23 & 0.218 & $-0.41(-1.07-0.24)$ \\
\hline & Yes & 9 & 11.78 & 40.66 & & & \\
\hline
\end{tabular}

Hedges's $g=$ effect size. $0.2,0.5$, and 0.8 are considered small, medium, and large effects, respectively. Degrees of freedom $(d f)=607$. 
changes in some cases may not be interpreted as a consequence of increased age, and how awareness of changes may trigger specific mental processes. The left side of the diagram illustrates five categories (experiencing positive changes, experiencing negative changes, ATOA, feeling unchanged, and purpose-driven experiences) that may enhance or decrease awareness of changes happening in individuals' lives. The center of the diagram illustrates variables that, irrespective of the changes that individuals are experiencing, may impact on individuals' evaluation of awareness of changes, and hence on scores on the AARC questionnaire. Indeed, some participants did not attribute changes to their increased age, experienced fluctuations in levels of awareness of changes, and had difficulty in understanding the AARC questionnaire. The right side of the diagram illustrates how being aware of changes may trigger mental processes related to the implementation of self-regulatory strategies, attention to healthy lifestyles, and social comparison. These mental processes could potentially be related to motivation to engage in interventions teaching individuals to adapt to age-related changes.

\section{Comparing levels of AARC gains and losses among individuals whose comments were and were not assigned to a specific category}

Results from the $t$-tests showing whether the extent of gains or losses for those individuals who had comments assigned to the given category was different to the extent of gains or losses reported by individuals whose comments were not assigned to the same category are reported in Tables $4 \mathrm{a}$ and $4 \mathrm{~b}$. Those participants who felt unchanged (small effect size) and/or found it difficult to answer the AARC questionnaire (large effect size) perceived fewer AARC gains than those participants whose comments were not assigned to these categories. Participants who reported purpose-driven experiences (small effect size) and attention to a healthy lifestyle and adaptation to age-related changes (small effect size) perceived more AARC gains than those participants whose comments were not assigned to these categories. Regarding the remaining seven categories, participants who commented on a specific category did not differ significantly in levels of AARC gains from those participants whose comments were not assigned to the same category.

Those participants who reported feeling unchanged (medium effect size) or described purpose-driven experiences (small effect size) perceived fewer AARC losses than those participants whose comments were not assigned to these categories. Participants who reported experiencing negative changes (small effect size), fluctuating levels of awareness of changes (large effect size), and disregarding the impact of their age on the changes they are experiencing (small effect size), perceived more AARC losses than participants whose comments were not assigned to these categories. Regarding the remaining five categories, participants whose comments were assigned to a specific category did not differ significantly in levels of AARC losses from those participants whose comments were not assigned to the same category.

\section{Discussion}

This study is the first to examine and categorize the open-ended comments made by UK individuals aged over 50 years in relation to their responses on the AARC questionnaire. From analysis of participants' comments about their AARC, we generated 10 categories, further grouped into 3 higherorder categories, suggesting that participants' levels of AARC gains and losses were shaped by a wide range of life events and psychosocial factors. However, in some cases, scores on the AARC questionnaire could be influenced by bias related to completion of the AARC items. Some of the factors (categories) identified in relation to perceptions of AARC were in line with the variables outlined in the Diehl and Wahl (2010) conceptual framework of AARC, whereas others were novel and had not been previously considered as potential contributors to AARC, for example, engagement in purpose-driven activities or in activities that distract from agerelated thoughts. Among the identified sources of inaccuracy related to the AARC questionnaire, perhaps the most important is that a sizeable proportion of participants scored high on AARC losses even though they did not interpret the experienced changes as being a consequence of aging. In the following paragraphs, the identified higher-order categories with their respective subcategories are discussed in relation to the Diehl and Wahl (2010) conceptual framework of AARC. The higherorder category subjective experiences while aging will be discussed first, followed by mental process of awareness of changes and factors impacting evaluation of awareness of changes. Finally, we will consider how study results provide possible interpretations for the associations of AARC with health outcomes.

Most of the categories that we identified (experiencing negative changes, experiencing positive changes, attitudes toward aging, and purpose-driven experiences) within the higher-order category subjective experiences while aging corroborate the hypothesized roles of health status, experience of limitations, current life events, age stereotyping, and personal goals as factors influencing the formation of AARC (Diehl and Wahl, 2010; Sabatini et al., 2021). 
However, our results suggest a more complex picture. Whereas so far theoretical and empirical literature considered abandoned goals and age-related roles as factors increasing awareness of age-related losses, we found that those individuals engaged in pursuing life goals (e.g. volunteering) perceived more gains and fewer losses than those not engaged in pursuing life goals. Hence, future interventions could enhance engagement in life goals as a way of promoting more positive experiences of aging. In line with Terror Management Theory (Burke et al., 2010), it may be that undertaking roles and hobbies typically assumed by older people increases awareness of mortality, negative emotions, and negative self-perceptions (including higher AARC losses) only when individuals are not engaged in activities that convey a high sense of purpose and self-efficacy. Terror Management Theory (Burke et al., 2010; Greenberg et al., 1986) indeed assumes that increasing age and death awareness give rise to anxiety only among those individuals who do not have a sense of purpose and/or high levels of self-efficacy.

Alternatively, it may be that the engagement in certain roles such as caring for grandchildren acts as a full-time occupation that reduces individuals' time to reflect on and worry about negative changes (Bordone and Arpino, 2015). Finally, some participants reported "feeling unchanged"; these individuals perceived fewer AARC gains and losses compared to those who did not feel unchanged. This empirically supports the hypothesis that those individuals who are less self-reflective may maintain a more consistent self-concept and hence report fewer AARC gains and losses, regardless of the amount of objective changes experienced (Diehl and Wahl, 2010; Kaufman, 1986). Future studies could explore whether levels of introspection mediate the effects of antecedents on subjective perceptions of AARC.

The second higher-order category mental process of awareness of changes corroborates Diehl and Wahls' (2010) hypothesis that perceptions of AARC give rise to a series of psychological processes involving self-regulation and meaning-making. In line with the Two-Process Framework (Brandtstädter and Rothermund, 2002), for some individuals AARC was a precondition for developing the intention to engage in an "healthy lifestyle and/or in selfregulation" (e.g. abandonment of old hobbies for less physically demanding ones). Moreover, these individuals scored higher on AARC gains compared to those who did not engage in such behaviors, confirming that perceived gains can be maintained through adaptation even when individuals experience negative changes (Baltes, 1987; Brandtstädter and Rothermund, 2002; Wilton-Harding and Windsor, 2021). For a small proportion of participants,
AARC triggered favorable "social comparison" (Festinger, 1954), meaning that they compared themselves with someone experiencing more negative changes than them. Age-Stereotype Internalization and Dissociation Theory posits that becoming aware of age-related changes can give rise to concerns about meeting those negative age stereotypes that individuals have internalized early in life. Consequently, to counteract negative thoughts and worries, individuals often distance themselves from their peers through favorable social comparison (Weiss and Kornadt, 2018).

The last higher-order category factors impacting evaluation of awareness of changes incudes three categories covering potential sources of bias related to the use of the AARC questionnaire. Almost onethird of participants disregarded the impact of their increased age on the changes experienced, yet on average they perceived more AARC losses than participants whose comments did not fit into this category. This means that several individuals reported high AARC losses despite attributing their changes to other factors. As the concept of AARC (Diehl and Wahl, 2010) implies that people are both aware of changes and also attribute such changes to their increased age, scores on the AARC questionnaire on some occasions may not accurately capture individuals' AARC. Recent evidence confirms that the tendency to causally attribute changes to increased age differs among individuals (Rothermund et al., 2021). As attributing changes to increased age enhances awareness of limited time to live (Burke et al., 2010), the tendency of some individuals with high levels of AARC losses to attribute changes to causes other than their age may be an emotional reaction to decrease the negative thoughts associated with awareness of mortality (Hobfoll, 2002; Leventhal et al., 2016; Rosenstock, 1974).

Participants' comments suggest that difficulty when answering the AARC questionnaire could be reduced by including a "non-applicable" answer option, specifying the comparative time frame in the item stem, and for UK use, substitute some American English words with more common alternatives in British English. Finally, some individuals experienced fluctuating levels of awareness of changes depending on several aspects of their mental and physical health. Micro-longitudinal research studies also document day-to-day fluctuation in levels of AARC gains and losses within the same person (Neupert and Bellingtier, 2017; Zhu and Neupert, 2020). Daily fluctuation in AARC is related to fluctuation in other variables such as levels of positive and negative affect (Neupert and Bellingtier, 2017) and control beliefs (Zhang and Neupert, 2020). As daily fluctuation in AARC influences daily cognitive performance (O'Brien et al., 2020; 
Zhu and Neupert, 2020), the fluctuating nature of AARC gains and losses may limit the predictive accuracy of the AARC questionnaire. It would, therefore, be important in future research to control for variables (e.g. mood) that account for variability in AARC.

Study results may help to explain some of the existing associations of AARC with health outcomes. First, in line with gerontological literature (Carstensen et al., 2011; McGrath et al., 2019; Miche et al., 2014; Rubio et al., 2016), participants' comments show that with increasing age negative experiences mainly relate to physical health (e.g. recent illnesses), whereas positive experiences often relate to socio-emotional aspects (e.g. increased confidence and experience). Moreover, those participants who commented on experiencing negative changes scored higher on levels of AARC losses compared to those who did not commented on this category. This pattern of results may explain why more AARC losses are associated with worse mental and physical health, whereas more AARC gains are associated with higher mental health but not with physical health (Brothers et al., 2019; Sabatini et al., 2020a; 2020c).

Second, those participants who engaged in purpose-driven experiences (e.g. hobbies) perceived more AARC gains and fewer AARC losses than those participants not mentioning any engagement in activities. As high engagement in activities, high perceived gains, and low perceived losses are all related to better mental health, levels of engagement in activities may explain why individuals with high gains and low losses maintain good mental health over time (Chippendale, 2013; Dutt and Wahl, 2018; Grossman and Gruenewald, 2017; LindsaySmith et al., 2018; 2019; Simone and Haas, 2013; Wilton-Harding and Windsor, 2021). Third, the finding that some individuals attribute changes to increased age whereas others attribute them to illnesses raises the question of whether attributing changes to different factors leads to different behavioral reactions. A recent study showed that those individuals who attribute changes to aging perceive lower levels of control over the experienced changes (Rothermund et al., 2021). As a consequence, it may be that these individuals are more likely to opt for passive coping strategies (e.g. acceptance of changes). Future studies on SPA could explore whether the attribution of changes to increased age (AARC) act as a moderator of the association of SPA with engagement in healthy and adaptive behaviors.

\section{Strengths and limitations}

This study has two limitations. First, as analyses are based on a self-selected sample, study participants may have had strong positive or negative feelings when answering the questionnaire (Ogletree and Katz, 2020). Second, the sample included a majority of participants who were women, White, and welleducated. The study, however, also has strengths including a large sample and the conduct of both qualitative and quantitative analyses. Participants reported their spontaneous thoughts, and hence participants' comments are not biased by the research questions or hypotheses.

\section{Conclusion}

A wide range of factors impact on perceptions of AARC. Some of these factors corroborate the variables outlined in the Diehl and Wahl (2010) conceptual framework of AARC. Others such as engagement in purpose-driven activities or in activities that distract from age-related thoughts are novel and could be added to the conceptual framework of AARC. Overall, results support the ability of the AARC questionnaire to capture subjective experiences of age-related changes in physical, mental, and cognitive health, engagement in social activities and in healthy and adaptive behaviors. However, as we identified some issues related to use of the AARC questionnaire, accuracy in assessing AARC could be increased through some minor adjustments to the questionnaire. Finally, study results raise new questions for future research; for instance, the AARC may act as a moderator of the associations of more general SPA with engagement in healthy and adaptive behaviors. It also remains to be explored whether engagement in activities mediates the associations of higher AARC gains and lower AARC losses with better health.

\section{Conflict of interest}

None.

\section{Funding}

This work was supported by the University of Exeter College of Life and Environmental Sciences (School of Psychology), University of Exeter College of Medicine and Health, and the National Health and Medical Research Council Centre for Research Excellence in Cognitive Health (\#1100579 to Kaarin Anstey).

\section{Description of authors' roles}

SS served as principal investigator of the research, designed the study, conducted data analyses, and took the lead in writing the manuscript. 
LC contributed to the design of the study, analysis of data, and writing the manuscript.

OU contributed to analyses of data and provided feedback on the draft of the manuscript.

$\mathrm{AC}, \mathrm{HB}$, and $\mathrm{CB}$ contributed to data collection and design of the PROTECT study and provided feedback on the draft of the manuscript.

RC provided feedback on the draft of the manuscript.

\section{Acknowledgements}

The authors are grateful to the University of Exeter for funding a $\mathrm{PhD}$ scholarship for Serena Sabatini to carry out this work. This paper represents independent research funded by the National Institute for Health Research (NIHR) Biomedical Research Centre at South London and Maudsley NHS Foundation Trust and King's College London. This research was also supported by the National Institute for Health Research (NIHR) Applied Research Collaboration (ARC) South-West Peninsula. The views expressed are those of the author(s) and not necessarily those of the NHS, the NIHR or the Department of Health. The authors are grateful to Jessica Rundle for contributing to the analysis as second rater.

\section{Availability of data and materials}

This study was conducted using secondary data collected as part of the UK version of the PROTECT ongoing study. PROTECT data are available to investigators outside the PROTECT team after request and approval by the PROTECT Steering Committee. Data for the AARC questionnaire will be available from May 2022 .

\section{Supplementary material}

For supplementary material accompanying this paper visit https://doi.org/10.1017/S104161022100123X

\section{References}

Balcombe, N. R. and Sinclair, A. (2001). Ageing: definitions, mechanisms and the magnitude of the problem. Best Practice \& Research Clinical Gastroenterology, 15, 835-849. DOI 10.1053/bega.2001.0244.

Baltes, P. B. (1987). Theoretical propositions of life-span developmental psychology: on the dynamics between growth and decline. Developmental Psychology, 23, 611-626. DOI 10.1037/0012-1649.23.5.611.

Barnett, K., Mercer, S. W., Norbury, M., Watt, G., Wyke, S. and Guthrie, B. (2012). Epidemiology of multimorbidity and implications for health care, research, and medical education: a cross-sectional study. The Lancet, 380, 37-43. DOI 10.1016/S0140-6736(12)60240-2.

Barrett, A. E. (2003). Socioeconomic status and age identity: the role of dimensions of health in the subjective construction of age. The fournals of Gerontology, Series B: Psychological Sciences and Social Sciences, 58, 101-109. DOI 10.1093/geronb/58.2.S101.

Bordone, V. and Arpino, B. (2015). Do grandchildren influence how old you feel? fournal of Aging and Health, 28, 1055-1072. DOI 10.1177/0898264315618920.

Brandtstädter, J. and Rothermund, K. (2002). The life-course dynamics of goal pursuit and goal adjustment: a two-process framework. Developmental Review, 22, 117-150. DOI 10.1006/drev.2001.0539.

Brothers, A. F., Gabrian, M., Wahl, H.-W. and Diehl, M. K. (2016). Future time perspective and awareness of age-related change: examining their role in predicting psychological well-being. Psychology and Aging, 31, 605617. DOI 10.1037/pag0000101.

Brothers, A. F., Gabrian, M., Wahl, H.-W. and Diehl, M. K. (2019). A new multidimensional questionnaire to assess awareness of age-related change (AARC). The Gerontologist, 59, e141-e151. DOI 10.1093/geront/gny006.

Brothers, A. F., Kornadt, A. E., Nehrkorn-Bailey, A., Wahl, H.-W. and Diehl, M. K. (2020). The effects of age stereotypes on physical and mental health are mediated by self-perceptions of aging. The fournals of Gerontology, 76, 845-857. DOI 10.1093/geronb/gbaa176.

Brothers, A. F., Miche, M., Wahl, H.-W. and Diehl, M. K. (2017). Examination of associations among three distinct subjective aging constructs and their relevance for predicting developmental correlates. The fournals of Gerontology, Series B: Psychological Sciences and Social Sciences, 72, 547-560. DOI 10.1093/geronb/gbv085.

Burke, B. L., Martens, A. and Faucher, E. H. (2010). Two decades of terror management theory: a meta-analysis of mortality salience research. Personality and Social Psychology Review, 14, 155-195. DOI 10.1177/ 1088868309352321.

Carstensen, L. L. 1993. Motivation for social contact across the life span: A theory of socioemotional selectivity. In: J. E. Jacobs (Ed.), Current Theory and Research in Motivation (pp. 209-254). Lincoln, NE: University of Nebraska Press.

Carstensen, L. L. et al. (2011). Emotional experience improves with age: evidence based on over 10 years of experience sampling. Psychology and Aging, 26, 21-33. DOI 10.1037/a0021285.

Chippendale, T. (2013). Factors associated with depressive symptoms among elders in senior residences: the importance of feeling valued by others. Clinical Gerontologist, 36, 162-169. DOI 10.1080/07317115.2012 .749321 .

Cohen, J. (1960). A coefficient of agreement for nominal scales. Educational and Psychological Measurement, 20, 37-46.

Dieh1, M. K. and Wahl, H.-W. (2010). Awareness of agerelated change: examination of a (mostly) unexplored concept. The fournals of Gerontology, Series B: Psychological Sciences and Social Sciences, 65B, S340-S350. DOI 10.1093/ geronb/gbp 110 .

Diehl, M. K. et al. (2014). Awareness of aging: theoretical considerations on an emerging concept. Developmental Review, 34, 93-113. DOI 10.1016/j.dr.2014.01.001. 
Dutt, A. J., Gabrian, M. and Wahl, H.-W. (2016). Developmental regulation and awareness of age-related change: a (mostly) unexplored connection. The fournals of Gerontology, Series B: Psychological Sciences and Social Sciences, 73, 934-943. DOI 10.1093/geronb/gbw084.

Dutt, A. J. and Wahl, H.-W. (2018). Future time perspective and general self-efficacy mediate the association between awareness of age-related losses and depressive symptoms. European fournal of Ageing, 16, 227-236. DOI $10.1007 / \mathrm{s} 10433-018-0482-3$.

Elliott, R., Fischer, C. T. and Rennie, D. L. (1999). Evolving guidelines for publication of qualitative research studies in psychology and related fields. British fournal of Clinical Psychology, 38, 215-229. DOI 10.1348/ 014466599162782.

English, A. N., Bellingtier, J. A. and Neupert, S. D. (2019). It's "the Joneses": the influence of objective and subjective socioeconomic status on subjective perceptions of aging. European fournal of Ageing, 16, 121-128. DOI 10.1007/s10433-018-0475-2.

Festinger, L. (1954). A theory of social comparison processes. Human Relations, 7, 117-140.

Grbich, C. (2012). Qualitative Data Analysis: An Introduction. Los Angeles, CA: Sage.

Greenberg, J., Pyszczynski, T. and Solomon, S. 1986. The causes and consequences of a need for self-esteem: A terror management theory. In: R. F. Baumeister (Ed.), Public Self and Private Self (pp. 189-192). New York, NY: Springer.

Grossman, M. R. and Gruenewald, T. L. (2017). Caregiving and perceived generativity: a positive and protective aspect of providing care? Clinical Gerontologist, 40, 435-447. DOI 10.1080/07317115.2017.1317686.

Hobfoll, S. E. (2002). Social and psychological resources and adaptation. Review of General Psychology, 6, 307-324. DOI 10.1037/1089-2680.6.4.307.

Hsieh, C.-M. (2005). Age and relative importance of major life domains. Fournal of Aging Studies, 19, 503-512. DOI 10.1016/j.jaging.2005.07.001.

Jaconelli, A., Terracciano, A., Sutin, A. R., Sarrazin, P., Raffard, S. and Stephan, Y. (2017). Subjective age and dementia. Clinical Gerontologist, 40, 106-113. DOI 10.1080/07317115.2016.1187695.

Kaspar, R., Gabrian, M., Brothers, A. F., Wahl, H.-W. and Diehl, M. K. (2019). Measuring awareness of age-related change: development of a 10-Item short form for use in large-scale surveys. The Gerontologist, 59, e130-e140. DOI 10.1093/geront/gnx213.

Kaufman, S. R. (1986). The Ageless Self: Sources of Meaning in Late Life. Madison, WI: University of Wisconsin Press.

Kingston, A., Robinson, L., Booth, H., Knapp, M. and Jagger, C. (2018). Projections of multi-morbidity in the older population in England to 2035: estimates from the population ageing and care simulation (PACSim) model. Age and Ageing, 47, 374-380. DOI 10.1093/ageing/afx201.

Kornadt, A. E., Hess, T. M., Voss, P. and Rothermund, K. (2018). Subjective age across the life span: a differentiated, longitudinal approach. The fournals of Gerontology, Series B: Psychological Sciences and Social Sciences, 73, 767-777. DOI 10.1093/geronb/gbw072.

Kornadt, A. E., Kessler, E.-M., Wurm, S., Bowen, C. E., Gabrian, M. and Klusmann, V. (2019). Views on ageing: a lifespan perspective. European fournal of Ageing, 17, 387-401. DOI 10.1007/s10433-019-00535-9.

Lakens, D. (2013). Calculating and reporting effect sizes to facilitate cumulative science: a practical primer for t-tests and ANOVAs. Frontiers in Psychology, 4, 863. DOI 10.3389/fpsyg.2013.00863.

Lawton, M. P. (1975). The Philadelphia geriatric center morale scale: a revision. fournal of Gerontology, 30, 85-89.

Leventhal, H., Phillips, L. A. and Burns, E. (2016). The Common-Sense Model of Self-Regulation (CSM): a dynamic framework for understanding illness selfmanagement. Fournal of Behavioral Medicine, 39, 935-946. DOI 10.1007/s10865-016-9782-2.

Levy, B. R. (2017). Age-stereotype paradox: opportunity for social change. The Gerontologist, 57, S118-S126. DOI 10.1093/geront/gnx059.

Lindsay-Smith, G., Eime, R., O'Sullivan, G., Harvey, J. and van Uffelen, J. G. Z. (2019). A mixed-methods case study exploring the impact of participation in community activity groups for older adults on physical activity, health and wellbeing. BMC Geriatrics, 19, 243. DOI 10.1186/ s12877-019-1245-5.

Lindsay-Smith, G., O'Sullivan, G., Eime, R., Harvey, J. and Van Uffelen, J. G. Z. (2018). A mixed methods case study exploring the impact of membership of a multiactivity, multicentre community group on social wellbeing of older adults. BMC Geriatrics, 18, 226. DOI 10.1186/ s12877-018-0913-1.

McGrath, R., Al Snih, S., Markides, K., Hall, O. and Peterson, M. (2019). The burden of health conditions for middle-aged and older adults in the United States: disability-adjusted life years. BMC Geriatrics, 19, 100. DOI 10.1186/s12877-019-1110-6.

Miche, M., Wahl, H.-W., Diehl, M. K., Oswald, F., Kaspar, R. and Kolb, M. (2014). Natural occurrence of subjective aging experiences in community-dwelling older adults. The fournals of Gerontology, Series B: Psychological Sciences and Social Sciences, 69, 174-187. DOI 10.1093/ geronb/gbs 164 .

Montepare, J. M. (2019). An exploration of subjective age, actual age, age awareness, and engagement in everyday behaviors. European fournal of Ageing, 17, 299-307. DOI 10.1007/s10433-019-00534-w.

Neuman, W. L. (2011). Social Research Methods: Qualitative and Quantitative Approaches. Whitewater, WI: Pearson.

Neupert, S. D. and Bellingtier, J. A. (2017). Aging attitudes and daily awareness of age-related change interact to predict negative affect. The Gerontologist, 57, S187S192. DOI 10.1093/geront/gnx055.

O'Brien, E. L., Torres, G. E. and Neupert, S. D. (2020). Cognitive interference in the context of daily stressors, daily awareness of age-related change, and general aging attitudes. The fournals of Gerontology, Psychological Sciences: Series B, 76(5), 920-929. DOI 10.1093/geronb/gbaa155.

Ogletree, A. and Katz, B. (2020). How do older adults recruited using MTurk differ from those in a national probability sample? The International fournal of Aging and Human Development, 93(2), 700-721. DOI 10.1177/ 0091415020940197.

Polit, D. F. and Beck, C. T. (2004). Nursing Research: Principles and Methods. Philadelphia, PA: Lippincott Williams and Wilkins. 
Pope, C., Ziebland, S. and Mays, N. (2000). Analysing qualitative data. BMF, 320, 114-126. DOI 10.1136/bmj.320 .7227 .114 .

Richards, L. (2015). Handling Qualitative Data: A Practical Guide. London: Sage.

Rosenstock, I. M. (1974). Historical origins of the health belief model. Health Education Monographs, 2, 328-335. DOI 10.1177/109019817400200403.

Rothermund, K. et al. (2021). Age-related attributions of experienced changes in life: origins and implications. The Fournals of Gerontology, Series B: Psychological Sciences and Social Sciences, 76, 881-893. DOI 10.1093/geronb/ gbaa 160.

Royall, D. R., Lauterbach, E. C., Kaufer, D., Malloy, P., Coburn, K. L. and Black, K. J. (2007). The cognitive correlates of functional status: a review from the Committee on Research of the American Neuropsychiatric Association. The Fournal of Neuropsychiatry and Clinical Neurosciences, 19, 249-265. DOI 10.1176/jnp.2007.19.3.249.

Rubio, L., Dumitrache, C., Cordon-Pozo, E. and Rubio-Herrera, R. (2016). Coping: impact of gender and stressful life events in middle and in old age. Clinical Gerontologist, 39, 468-488. DOI 10.1080/07317115.2015 .1132290 .

Sabatini, S. et al. (2020a). Associations of awareness of agerelated change with emotional and physical well-being: a systematic review and meta-analysis. The Gerontologist, 60, e477-e490. DOI 10.1093/geront/gnz101.

Sabatini, S. et al. (2020b). International relevance of two measures of awareness of age-related change (AARC). BMC Geriatrics, 20, 359. DOI 10.1186/s12877-020-01767-6.

Sabatini, S. et al. (2020c). The cross-sectional relationship between pain and awareness of age-related changes. British Fournal of Pain, 15(3), 335-344. DOI 10.1177/ 2049463720961798.

Sabatini, S. et al. (2021). Cross-sectional association between objective cognitive performance and perceived age-related gains and losses in cognition. International Psychogeriatrics, 33, 727-741. DOI 10.1017/ S1041610221000375.

Sabatini, S. et al. (In Press). What does feeling younger or older than one's chronological age mean to men and women? Qualitative and quantitative findings from the PROTECT study. Psychology and Health.

Sandelowski, M. and Barroso, J. (2003). Classifying the findings in qualitative studies. Qualitative Health Research, 13, 905-923. DOI 10.1177/1049732303253488.

Simone, P. M. and Haas, A. L. (2013). Frailty, leisure activity and functional status in older adults: relationship with subjective well being. Clinical Gerontologist, 36, 275-293. DOI 10.1080/07317115.2013.788114.
Steverink, N., Westerhof, G. J., Bode, C. and Dittmann-Kohli, F. (2001). The personal experience of aging, individual resources, and subjective well-being. The Fournals of Gerontology, Series B: Psychological Sciences and Social Sciences, 56, 364-373. DOI 10.1093/geronb/56.6.P364.

Teal, R. et al. (2015). Applying cognitive interviewing to inform measurement of partnership readiness: a new approach to strengthening community-academic research. Progress in Community Health Partnerships: Research, Education, and Action, 9, 513-519. DOI 10.1353/cpr.2015 .0083 .

Timmer, E., Steverink, N. and Dittmann-Kohli, F. (2002). Cognitive representations of future gains, maintenance, and losses in the second half of life. The International fournal of Aging and Human Development, 55, 321-339. DOI 10.1177/009141500205500401.

United Nations. (2019). Levels of trends in population ageing. https://www.unsecretariat.net/sections/issues-depth/ ageing/index.html.

Voss, P., Kornadt, A. E., Hess, T. M., Fung, H. H. and Rothermund, K. (2018). A world of difference? Domainspecific views on aging in China, the US, and Germany. Psychology and Aging, 33, 595-606. DOI 10.1037/ pag0000237.

Weiss, D. and Kornadt, A. E. (2018). Age-stereotype internalization and dissociation: contradictory processes or two sides of the same coin? Current Directions in Psychological Science, 27, 477-483. DOI 10.1177/ 0963721418777743.

Westerhof, G. J. et al. (2014). The influence of subjective aging on health and longevity: a meta-analysis of longitudinal data. Psychology and Aging, 29, 793-802. DOI 10.1037/a0038016.

Whittemore, R., Chase, S. K. and Mandle, C. L. (2001). Validity in qualitative research. Qualitative Health Research, 11, 522-537. DOI 10.1177/104973201129119299.

Wilton-Harding, B. and Windsor, T. D. (2021). Awareness of age-related change, future time perspective, and implications for goal adjustment in older adulthood. Aging E Mental Health, 1-9. DOI 10.1080/13607863.2021 .1893269 .

Zhang, S. and Neupert, S. D. (2020). Within-and betweenperson relationships among health, awareness of aging, and control beliefs: a micro-longitudinal study. The fournals of Gerontology, Series B: Psychological Sciences and Social Sciences, 39(2), 282-298. DOI 10.1093/geronb/gbaa180.

Zhu, X. and Neupert, S. D. (2020). Dynamic awareness of age-related losses predict concurrent and subsequent changes in daily inductive reasoning performance. British Fournal of Developmental Psychology, 39, 282-298. DOI $10.1111 /$ bjdp.12344. 